\title{
Response of Residential Electricity Demand to Price: The Effect of Measurement Error
}

\author{
Anna Alberini \\ Department of Agricultural \\ Economics, University of \\ Maryland, US \\ and \\ Centre for Energy Policy and \\ Economics (CEPE), ETH Zurich \\ and
}

\author{
Massimo Filippini \\ Centre for Energy Policy and \\ Economics (CEPE), ETH Zurich \\ and \\ Department of Economics, \\ University of Lugano, \\ Switzerland
}

Last revision: 10 March 2011

\begin{abstract}
In this paper we present an empirical analysis of the residential demand for electricity using annual aggregate data at the state level for 48 US states from 1995 to 2007. Earlier literature has examined residential energy consumption at the state level using annual or monthly data, focusing on the variation in price elasticities of demand across states or regions, but has failed to recognize or address two major issues. The first is that, when fitting dynamic panel models, the lagged consumption term in the right-hand side of the demand equation is endogenous. This has resulted in potentially inconsistent estimates of the long-run price elasticity of demand. The second is that energy price is likely mismeasured.

To address these issues, we estimate a dynamic partial adjustment model using the Kiviet corrected Least Square Dummy Variables (LSDV) (1995) and the Blundell-Bond (1998) estimators. We find that the long-term elasticities produced by the Blundell-Bond system GMM methods are largest, and that from the bias-corrected LSDV is greater than that from the conventional LSDV. From an energy policy point of view, the results obtained using the Blundell-Bond estimator where we instrument for price imply that a carbon tax or other pricebased policy may be effective in discouraging residential electricity consumption and hence curbing greenhouse gas emissions in an electricity system mainly based on coal and gas power plants.
\end{abstract}

JEL Classification: D, D2, Q, Q4, Q5.

Keywords: residential electricity and gas demand; US states, panel data, dynamic panel data models, partial adjustment model. 


\section{Introduction}

Inducing residential consumers to use electricity more efficiently has been a growing concern for the government in many countries because of climate change, security of supply and an electric power system based on power plants that mainly use nonrenewable resources such as coal and oil. Buildings account for some $30-40 \%$ of energy use, and policy instruments are currently in use or are being considered at many locales to help reduce energy use in the residential sector. These include price increases through the introduction of an ecological tax, mandatory energy-saving measures in the construction and renovation of buildings, and subsidies to promote the construction and renovation of energy-saving buildings. These measures would encourage conservation or energy efficiency investments. Both are currently considered important for reducing $\mathrm{CO}_{2}$ emissions, especially in the US, where coal-fired power plants account for a large share of electricity generation.

The effectiveness of a price policy depends upon the price elasticity of demand for electricity. Underlying this energy pricing policy question is the proper specification and estimation of an electricity demand equation. Much literature in the last 30 years has focused on the use of aggregate nationwide or state-level data to fit energy demand equations and estimate its elasticity with respect to price.

The majority of these studies have used panel data and a dynamic adjustment approach (Halvorsen (1975), Houthakker (1980), Baltagi et. Al. (2002), Kamerschen and Porter (2004), Bernstein and Griffin (2006) and Paul et al. (2009)). Because they use panel data, most of these studies control for unobserved heterogeneity using fixed or random effects, sometimes combined with a simple instrumental variable approach. The short-run price elasticities of the 
residential demand for electricity in the US range from -0.20 to -0.35 , and the long-run price elasticity vary even more widely, ranging from -0.3 to -0.8 .

With the exception of Baltagi et al. (2002), however, most of these studies have failed to recognize and address the possible endogeneity of lagged consumption, which is often included in the right-hand side of the demand equation, and so the estimates of the price elasticity are suspect. Moreover, these studies are generally based on data from the 1970s and the 1980s, and there is no reason to believe that the same responsiveness to price changes observed in periods of rapidly increasing prices (e.g., the 1970s and early 1980s) would hold in periods of stable or decreasing energy prices (Haas and Schipper, 1998).

Despite the potentially serious consequences on the estimated price elasticity, in the literature little attention has been devoted to the possibility that the price of energy might be mismeasured. In two recent studies that use household-level data, Alberini et al. (forthcoming) and Fell et al. (2010) discuss the implications of energy prices that are measured with an error term and implement different approaches to address this problem. Neither exploits the dynamic nature of the data.

We wish to examine how sensitive the price elasticities are to the choice of the econometric estimation technique. From a policy perspective, understanding what drives the different results is important, because the different estimates of the price elasticity imply different conclusions about the effects of electricity pricing policies.

In this paper, we ask three research questions. First, what are the current short-run and long-run price elasticities of the residential electricity demand in the US? Second, are the estimates of the elasticity robust to attempts to address a major econometric problem with dynamic adjustment models of electricity demand, namely, the correlation between the lagged 
demand and the error term? Third, how are results affected by the possibility that the energy price is mismeasured?

To answer these questions, we use a panel of data documenting annual residential energy demand at the state level in the US for 1995-2007. We estimate a partial adjustment model where the dependent variable is log electricity use per capita in the state (i.e., electricity consumption in the residential sector, divided by population), and the regressors, in addition to the lagged dependent variable, include the log transformations of the price of electricity, the price of the closest substitute (gas), income and other controls.

Holding the time period and the specification the same, we focus on the role of different estimation techniques suited for dynamic panel models. We experiment with biascorrected least-squares dummy variables and Blundell-Bond GMM estimation, and further instrument for price to address the measurement error. We find that changing the estimation technique alone results in changes in the long-run price elasticity of electricity demand of up to $70 \%$, whereas the short-term estimates can be as far apart as $88 \%$ of each other.

The remainder of the paper is organized as follows. We briefly review the literature in section 2. The model is described in section 3. The data are described in section 4. The econometric methods are described in section 5. The estimation results are presented in Section 5. Section 6 concludes.

\section{Literature Review}

Earlier efforts to study the residential electricity demand in the US using aggregate statelevel panels include Halvorsen (1975), Houthakker (1980), Baltagi et. Al. (2002), Kamerschen 
and Porter (2004), Bernstein and Griffin (2006) and Paul et al. (2009). ${ }^{1}$ Virtually all of these studies include similar controls, such as weather and income, in the right-hand side of the model, but differ for the time period covered by the sample, the specification of the price variable, and the estimation procedure.

Regarding the time period covered, much of this earlier work relies on data from the 1970s and 1980s, and only Bernstein and Griffin (2006), and Paul et al. (2009) cover the years until 2006. The majority of these studies use average energy prices. In terms of specification of the model and estimation technique, fixed or random effects models were used, combined with a simple instrumental variable approach. The only study that uses recent advances in the estimation of dynamic panel data models (e.g., the Anderson and Hsiao, 1982, and Arellano and Bond, 1991, estimators) is Baltagi et. al. (2002), which, however, is based on old data (19701990).

The two most recent studies (Bernstein and Griffin, 2006, and Paul et al., 2008) use more recent data and dynamic models, but do not attempt to address the possibility that lagged consumption is endogenous, when included in the right-hand side of the regression equation. Specifically, Bernstein and Griffin (2006) estimate the electricity and gas consumption in the residential sector in the US using a panel of data at the state level from 1977 to 2004 . The main goal of their study is to determine whether the relationship between prices and demand differs at the regional level.

They adopt a partial adjustment model that includes the average prices of electricity and gas, one-year lags for each of these variables, and lagged electricity consumption. Controls include per capita income and a climate index. These authors use a log-log functional form,

\footnotetext{
${ }^{1}$ For a recent exhaustive review on studies estimating the residential electricity demand see Espey and Espey (2004).
} 
state-specific fixed effects, and year effects. When attention is restricted to residential electricity demand, the short- and long-term own price elasticities are -0.243 and -0.32 , respectively. Bernstein and Griffin (2006) conclude that residential electricity demand is price-inelastic and that these elasticities are virtually the same as those from studies performed 20 years earlier.

Paul et al. (2008) use monthly average price and electricity demand data at the state level for 1990-2006. They specify partial adjustment models that include state fixed effects, monthly HDDs and CDDs, and daylight hours, among other controls. The price elasticities of demand are allowed to vary across states and regions. When averaged over the nation, the own price elasticity is -0.13 in the short run and -0.36 in the long run, confirming once again that the demand for electricity is price-inelastic.

Paul et al. argue that price is exogenous in the demand equation, but raise the possibility that demand might be serially correlated, in which case lagged demand and the state-specific fixed effects would be correlated, making the LSDV estimator biased and inconsistent. They report that attempts to instrument for lagged electricity demand using past prices (plus all of the exogenous variables) or past prices and past demand (plus all of the exogenous variables) were unsuccessful and resulted in unstable estimates. They therefore report only the LSDV estimation results.

In sum, the two most recent studies on residential energy demand both use the same econometric technique, LSDV, which is based on the "within" variation in all variables. Furthermore, these two studies do not attempt to address two major econometric problems with dynamic adjustment electricity demand models, namely, the correlation between the lagged demand and the error term, and the possibility that the average price of energy at the state level is affected by measurement error. 
To our knowledge, the issue of mismeasured energy prices is rarely addressed in the literature. Alberini et al. (forthcoming) instrument for the price of electricity faced by households using state-level averages, which do not exploit the dynamic aspect of the data. They further check what happens to the estimates of the price elasticities when attention is restricted to those households for whom the measurement error is argued to be the smallest. Fell et al. (2010) take an entirely different approach, relying on a structural model that is estimated using GMM and omits prices altogether. As we explain below, in this paper we examine how the price elasticities change when econometric techniques are used that address all of these concerns.

\section{The Model}

Residential demand for energy is derived from the demand for a warm house, cooked food, hot water, lighting, etc., and can be specified using the basic framework of household production theory. ${ }^{2}$ Households purchase "goods" on the market which serve as inputs to produce the "commodities" that enter in the argument of the household's utility function. ${ }^{3}$

In the US residential sector, the most important fuels used are electricity (100\% of the households) and gas ( $\sim 60 \%$ of the households). Fue1 oil ( $7 \%$ of the households), liquefied petroleum gas (LPG; $\sim 1.5 \%$ of the households), and kerosene $\quad(\sim 1.5 \%$ of the households) are less important. Ignoring the less common fuels, we assume that a household combines electricity, gas and capital equipment to produce a composite energy commodity.

The production function of the composite energy commodity $S$ can be written as:

\footnotetext{
${ }^{2}$ See Thomas (1987) and Deaton and Muellbauer (1980). See Flaig (1990) and Filippini (1999) for an application of household production theory to electricity demand analysis.

${ }^{3}$ Approximately $45 \%$ of the energy used in a household is for appliances and lighting, whereas space heating, water heating and air conditioning account for $30 \%$.
} 


$$
S=S(E, G, C S)
$$

where $E$ is electricity, $G$ is gas, and $C S$ is the capital stock consisting of appliances. The output of the composite commodity $S$, namely energy services, is thus determined by the amount of electricity and gas purchased as well as the quantity of the capital stock of appliances.

Energy services $\mathrm{S}$ enters in the utility function of the household as an argument, along with aggregate consumption $X$. The utility function is influenced by household characteristics $\mathbf{Z}$ and by the weather in the area where the household resides. We denote climate and weather variables as W. Formally,

$$
U=U(S(E, G, C S), X ; \mathbf{Z}, \mathbf{W})
$$

The household maximizes utility subject to a budget constraint,

$$
Y-P_{S} \cdot S-X=0
$$

where $Y$ is money income and $P_{S}$ is price of the composite energy commodity. The price of aggregate consumption $\mathrm{X}$ is assumed to be one.

The solution to this optimization problem yields demand functions for E, G, CS and X:

$$
\begin{aligned}
& E^{*}=E^{*}\left(P_{E}, P_{G}, P_{C S}, Y ; \mathbf{Z}, \mathbf{W}\right) \\
& G^{*}=G^{*}\left(P_{E}, P_{G}, P_{C S}, Y ; \mathbf{Z}, \mathbf{W}\right) \\
& C S^{*}=C S^{*}\left(P_{E}, P_{G}, P_{C S}, Y ; \mathbf{Z}, \mathbf{W}\right) \\
& X^{*}=X^{*}\left(P_{E}, P_{G}, P_{C S}, Y ; \mathbf{Z}, \mathbf{W}\right)
\end{aligned}
$$

Equations (4)-(7) describe the long-run equilibrium of the household. This model is static in that it assumes an instantaneous adjustment to new equilibrium values when prices or income change. Specifically, it is assumed that the household can change both the rate of 
utilization and the stock of appliances, adjusting them instantaneously and jointly to variations in prices or income, so that the short-run and long-run elasticities are the same.

In this paper attention is restricted to the demand for electricity. Based on equation (4) and on the available data (see section 4) and using a log-log functional form we posit the static empirical model of electricity demand:

$$
\begin{gathered}
\ln E_{i t}=\beta_{i}+\beta_{P E} \ln P_{P E i t}+\beta_{G E} \ln P_{G E i t}+\beta_{I N C} \ln I N C_{i t}+\beta_{H S} \ln H S_{i t}+\beta_{H D D} \ln H D D_{i t}+ \\
+\beta_{C D D} \ln C D D_{i t}+\varepsilon_{i t}
\end{gathered}
$$

where $E_{i t}$ is aggregate electricity consumption per capita, $I N C_{i t}$ is income per capita, $P_{E i t}$ is the real average price of electricity, $P_{G i t}$ is the real average price of gas, $H S_{\text {it }}$ is household size, $H D D_{\text {it }}$ and $C D D_{\text {it }}$ are the heating and cooling degree days in state $i$ in year $t$, and $\varepsilon_{\text {it }}$ is the disturbance term. ${ }^{4}$ Since energy consumption and the regressors are in logarithms, the coefficients are directly interpreted as demand elasticities. The $\beta_{i}$ terms allow for unobserved state-specific heterogeneity. Depending on the assumptions one is prepared to make about their correlation with the other right-hand side variables in (8), they may be regarded as fixed intercepts ("fixed effects") or random variables ("random effects").

Actual electricity consumption may differ from the long-run equilibrium consumption, because the equipment stock cannot adjust easily to the long-run equilibrium. A partial adjustment mechanism allows for this situation. This model assumes that the change in log actual demand between any two periods $t-1$ and $t$ is only some fraction $(\lambda)$ of the difference between the logarithm of actual demand in period $t-1$ and the logarithm of the long-run equilibrium demand in period $t$. Formally,

\footnotetext{
${ }^{4}$ Functional forms commonly assumed when estimating ad-hoc energy demand models include the linear, semi-log and $\log$-log forms. One of the advantages of the log-log functional form is that the coefficients are directly interpretable as demand elasticities. Xiao et. al. (2007) show in an empirical analysis of residential energy demand that the log-linear model is superior to the linear model.
} 


$$
\ln E_{t}-\ln E_{t-1}=\lambda\left(\ln E_{t}^{*}-\ln E_{t-1}\right)
$$

where $0<\lambda<1$, and we have suppressed the $i$ subscript to avoid clutter.

This implies that given an optimum, but unobservable, level of electricity, demand only gradually converges towards the optimum level between any two time periods. Assume that desired energy use (for example, desired electricity consumption) can be expressed as $E_{t}^{*}=\alpha \cdot P_{E}^{\eta} \cdot P_{G}^{\theta} \cdot \exp (\mathbf{X} \boldsymbol{\gamma})$, where $\eta$ and $\theta$ are the long-term elasticities with respect to the price of electricity and gas, and $\mathrm{X}$ is a vector of variables influencing demand for energy, including income, climate, characteristics of the stock of housing, etc. On inserting this expression into (9), we get

$$
\ln E_{t}-\ln E_{t-1}=\lambda \ln \alpha+\lambda \eta \ln P_{E}+\lambda \theta \ln P_{G}+\lambda \mathbf{X} \boldsymbol{\gamma}-\lambda \ln E_{t-1}
$$

On re-arranging and appending an econometric error term, we obtain the regression equation:

$$
\ln E_{t}=\lambda \ln \alpha+\lambda \eta \ln P_{E}+\lambda \theta \ln P_{G}+\lambda \mathbf{X} \boldsymbol{\gamma}+(1-\lambda) \ln E_{t-1}+\varepsilon
$$

This expression shows that the short-run elasticities are the regression coefficients on the log prices, whereas the long-run elasticities can be computed by dividing these short-run elasticities (i.e., the coefficients on the $\log$ prices) by the estimate of $\lambda$. In turn, the latter is easily obtained as 1 minus the coefficient on $\ln E_{t-1}$.

In this paper, the dynamic version of the electricity demand model based on the partial adjustment hypothesis is specified as:

$$
\begin{gathered}
\ln E_{i t}=\beta_{i}+\beta_{E} \ln E_{i, t-1}+\beta_{P E} \ln P_{P E i t}+\beta_{G E} \ln P_{G E i t}+\beta_{I N C} \ln I N C_{i t}+\beta_{H S} \ln H S_{i t}+ \\
+\beta_{H D D} \ln H D D_{i t}+\beta_{C D D} \ln C D D_{i t}+\varepsilon_{i t} .
\end{gathered}
$$

In sum, in the remainder of this paper, we estimate equations (8) and (12), which we interpret as a static and dynamic model, respectively, of electricity consumption for the 
representative consumer in the US. The parameters of interest are the short- and long-run elasticities with respect to the price of electricity. Our goal is to see how the estimates of the elasticities change when i) we model unobserved heterogeneity using fixed or random effects, ii) we deploy alternate estimation techniques for the dynamic model, and iii) regard price as mismeasured.

\section{The Data}

We compiled annual data for all the states in the US (50 states plus the District of Columbia, for a total of 51 units) from 1995 to 2007 . For the purposes of this paper, however, attention is restricted to the contiguous US states (Alaska and Hawaii are excluded), and we further drop Rhode Island because of incomplete information. Descriptive statistics for the remaining 48 states are presented in table 1.

Residential electricity consumption figures and prices are provided by the Energy Information Agency. Population and household income are from the Bureau of Economic Analysis of the US Census Bureau. ${ }^{5}$ We obtained heating and cooling degree days from the National Climatic Data Center at NOAA. The typical size of a household is obtained by dividing population by the number of housing units, where the latter variable comes from the US Census Bureau.

\footnotetext{
${ }^{5}$ The price of electricity and gas, and income, are converted to real prices by dividing by the consumer price index (Bureau of Labor Statistics, 2010).
} 
Table 1. Definition of Variables and Descriptive Statistics. $N=624$.

\begin{tabular}{|c|c|c|c|c|c|}
\hline Variable & Label & Mean & Std. Dev. & Min. & Max. \\
\hline electricity demand per capita, KWh & el_kwh & 4537 & 1209 & 2147 & 7086 \\
\hline $\begin{array}{l}\text { price of electricity per KWh (1982-84 } \\
\text { dollars) }\end{array}$ & price per KWh & 0.048516 & 0.012534 & 0.029797 & 0.091198 \\
\hline $\begin{array}{l}\text { price of gas per cubic meter (1982-84 } \\
\text { dollars) }\end{array}$ & price per $\mathrm{m}^{3}$ & 0.005204 & 0.0015 & 0.002617 & 0.010445 \\
\hline population/detached houses & household size & 2.34673 & 0.164712 & 1.888274 & 2.994109 \\
\hline Income per capita (thou. 1982-84 dollars) & $\begin{array}{l}\text { Income per } \\
\text { capita }\end{array}$ & 14700 & 2346 & 10239 & 26120 \\
\hline heating degree days (base: $65^{\circ} \mathrm{F}$ ) & HDD & 5087.375 & 1998.374 & 555 & 10745 \\
\hline Cooling degree days (base: $65^{\circ} \mathrm{F}$ ) & CDD & 1142.109 & 795.8133 & 128 & 3870 \\
\hline
\end{tabular}

Two key variables in the model are the prices of electricity and gas. Regarding the electricity price, the only information available at the state level for the residential sector is the average price, which is calculated by the EIA as the revenue of the utilities coming from the residential sector divided by electricity sales to the residential sector (as documented by the utilities in the EIA Form 861 submitted every year to the agency). The average gas price used in this study is calculated by the EIA as the total sales divided by gas consumption in the residential sector.

We display the price of electricity (in real 1982-1984 dollars) for selected states (California, Texas, New York and Florida, the four largest in terms of population) in Figure 1. Figure 1 shows that electricity prices vary dramatically between states. They also vary within a state over time, but to a much lesser degree. We remind the reader that during our study period, electricity markets were regulated everywhere until about 2000. Several states allowed deregulation starting in or around 2000, but even so, the price and provision of electricity to 
residential and other customers is subject to the oversight and approval of the state public utility commission.

Figure 1: Price of electricity in selected states (cents per KWh, 1982-1984)

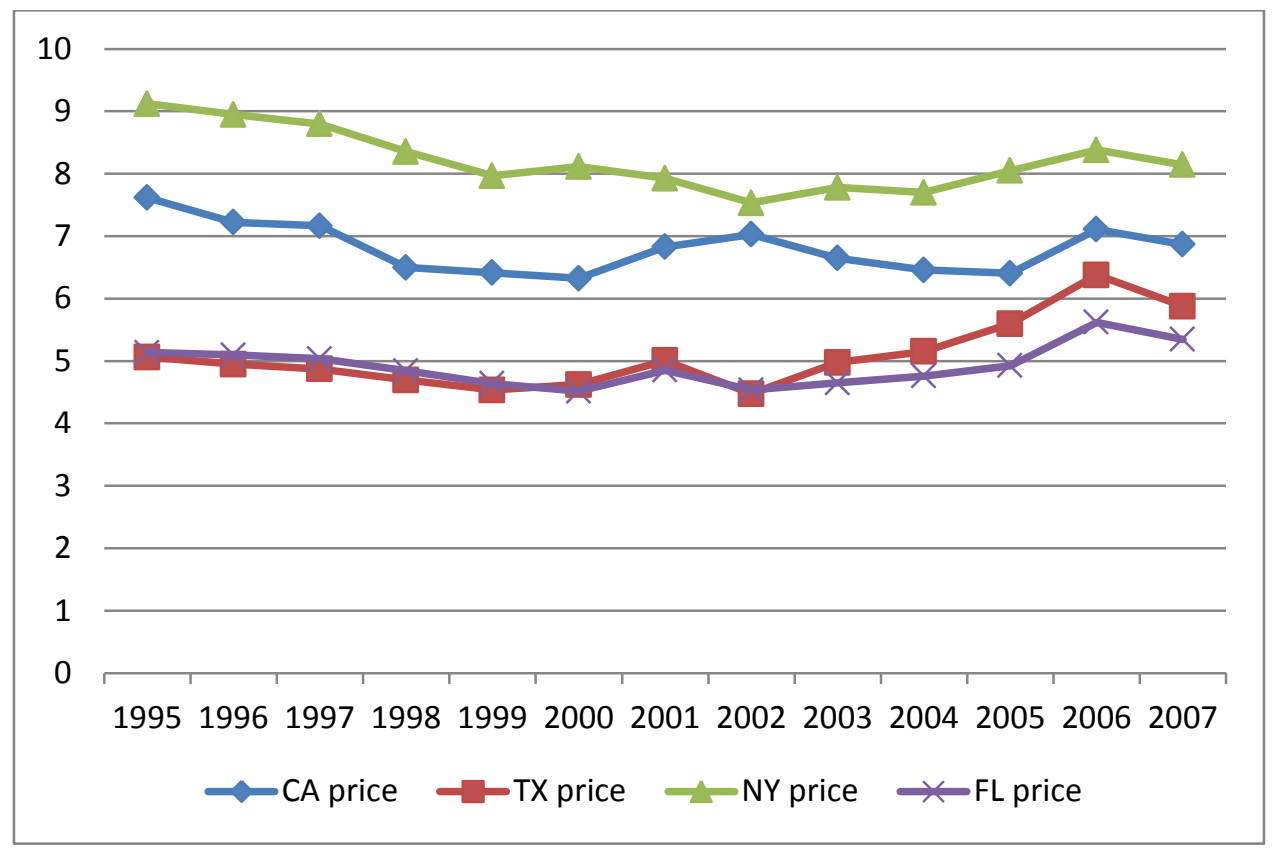

\section{Econometric Specification and Estimation}

\section{A. Econometric Techniques}

When static energy demand models are estimated using panel data, it is customary to account for unobserved heterogeneity using fixed or random effects. The appropriate estimation techniques are the "within" estimator (also termed LSDV, see Greene, 2007) and GLS (see Baltagi, 1996), respectively. We begin our empirical work with estimating the static model in equation (8) under these two alternate assumptions about the nature of the unobserved heterogeneity. 
Next, we turn to dynamic equation (12). Dynamic panel data models that include fixed or random effects are problematic. A major concern is that the lagged dependent variable in the right-hand side might be serially correlated and hence correlated with the error term, which makes the LSDV and GLS estimators (for models with fixed and random effects, respectively) biased and inconsistent, since $\left(y_{i, t-1}-\bar{y}_{i,-1}\right)$, where $y=\ln E$ and $\bar{y}_{i,-1}$ is the average lagged $\log$ consumption within state $i$, is correlated with $\left(\varepsilon_{i t}-\bar{\varepsilon}_{i}\right)$ (see Baltagi, 1995). The bias of the coefficient of the lagged dependent variable vanishes as T gets large, but the LSDV and the GLS estimators remain biased and inconsistent for $\mathrm{N}$ large and $\mathrm{T}$ small.

Specifically, assuming that the coefficient on the lagged dependent variable is positive, it can be shown that its OLS estimate is biased upwards, while the LSDV estimator is biased downwards. ${ }^{6}$ Therefore, a consistent estimate should lie between the two, which suggests a possible estimation approach.

Kiviet (1995) derives an approximation for the bias of the LSDV estimator when the errors are serially uncorrelated and the regressors are strongly exogenous, and proposes an estimator that is derived by subtracting a consistent estimate of this bias from the LSDV estimator. ${ }^{7}$ An alternative approach is to first-difference the data, thus eliminating the statespecific effects:

$$
\Delta y_{i t}=\gamma \cdot \Delta y_{i, t-1}+\Delta \mathbf{x}_{i t} \boldsymbol{\beta}+\Delta \varepsilon_{i t}
$$

where $\mathbf{x}$ denotes all exogenous regressors in the right-hand side of equation (12), and to use $y_{i, t-2}$ and $\Delta \mathbf{x}_{i t}$ as instruments for $\Delta y_{i, t-1}$ (Anderson and Hsiao, 1981).

\footnotetext{
${ }^{6}$ For a discussion on this issue see Nickell (1981) and Harris et al. (2008).

${ }^{7}$ Since the bias is negative if the true coefficient on the lagged dependent variable is positive, this means that we add a positive quantity to the LSDV estimator.
} 
Arellano and Bond (1991) point out that the latter approach is inefficient and argue that additional instruments can be obtaining by exploiting the orthogonality conditions that exist between the lagged values of $y_{i, t}$ and the disturbances in (13). ${ }^{8}$ The Arellano-Bond procedure is generalized method of moments (GMM) estimator that is implemented in two steps. In practice, the Arellano-Bond estimator has been shown to be biased in small sample, and the bias increases with the number of instruments and orthogonality conditions. Moreover, Arellano and Bond (1991) show that the asymptotic approximation of the standard errors of their two-step GMM estimator is biased downwards, and Judson and Owen (1999) and Arellano and Bond (1991) find that the one-step estimator outperforms the two-step estimator.

In addition to the possible "instability" of the Arellano-Bond estimator with respect to minor changes in the selection of the instruments (see Harris et al., 2008, page 254), one concern is that the above mentioned estimators were developed primarily for situations with large $\mathrm{N}$ and small T. In our case, $\mathrm{N}$ is modest and should be treated as fixed (since the number of U.S. states does not change), and $\mathrm{T}$ is small. Using Monte Carlo simulations, Judson and Owen (1999) show that with balanced dynamic panels characterized by $\mathrm{T} \leq 20$, and $\mathrm{N} \leq 50$, as is the case here, the Kiviet corrected LSDV (LSDVC) estimator of $\gamma$ (the coefficient on the lagged dependent variable) outperforms the Anderson-Hsiao and the Arellano-Bond estimators, in the sense that it has lower mean square errors. ${ }^{9}$ They also find that imposing restrictions on the number of lagged dependent variables and exogenous instruments to be used with the Arellano-Bond estimator does not materially reduce the performance of this technique.

\footnotetext{
${ }^{8}$ See Baltagi (2008), p. 154, for details on the efficiency issues and chapter 8 for a discussion of the orthogonality conditions.

${ }^{9}$ With unbalanced panels, by the time T reaches 30, Judson and Owen found the LSDV estimator without bias correction is superior to the Arellano-Bond estimators. Bruno (2005) develops the LSDVC estimator for unbalanced panel.
} 
Under the additional assumption of quasi-stationarity of $y_{i, t}, \Delta y_{i, t-1}$ is uncorrelated with $\varepsilon_{i t}$. Blundell and Bond (1998) suggest a "system" GMM estimation where one stacks the model in the levels and in the first differences, imposes the cross-equation restrictions that the coefficients entering in the two models be the same, and uses the full set of instruments (corresponding to the full set of orthogonality conditions for both models). Blundell and Bond report that in simulation the "system" GMM estimator is more efficient and stable than the Arellano-Bond procedure. Further, as shown by Hayakawa (2007), the small sample bias of the "system" GMM estimator is smaller than that of the Arellano-Bond estimator. This implies that this econometric approach can also be used with relatively small data sets.

Therefore, based on this discussion and the fact that our dataset has $\mathrm{N}=48$ and $\mathrm{T}=13$, we estimate our dynamic models using the LSDVC and the Blundell-Bond GMM (BB-GMM) estimators with various restrictions on the number of orthogonality conditions. ${ }^{10}$ Moreover, in this first round of estimation, we treat the price of electricity, the price of gas, HDDs, CDDs, population and household size as exogenous variables.

\section{B. Prices and Measurement Errors}

As mentioned, we use the average price of electricity to residential customers, as reported by the EIA, and in our first round of estimation we regard it as exogenous. Bernstein and Griffin (2006) and Paul et al. (2009) consider the average price as exogenous on the grounds that it is set by regulation. In what follows, we discuss three issues with the price variable,

\footnotetext{
${ }^{10} \mathrm{~A}$ small $\mathrm{N}$ constrains the researcher to limit the number of instruments used for estimation. With a small $\mathrm{N}$, it is important to keep the number of instruments less than or equal to the number of groups (or cross-sectional units, which in our case are the states) to improve efficiency and prevent the Sargan test from becoming weak. We use the second lag of the dependent variable as an instrument. We experimented with further lags, but observed a considerable loss of efficiency and rather imprecise estimates. See Cameron and Trivedi (2009) for a discussion of this issue.
} 
namely i) whether average price is the appropriate price variable, ii) whether average price is endogenous or exogenous, and iii) the issue of measurement error.

Regarding i), there is considerable debate in the literature as to whether consumers respond to the marginal price or to the average price, which are different from one another in the presence of fixed fees and/or block pricing. ${ }^{11}$ When utilities apply block pricing, the theoretically appropriate measure is block marginal price (Taylor, 1975; White and Reiss, 2005), which is clearly not available in this case. However, Shin (1985) argues that households will respond to average price, which is easily calculated from the electricity bill, rather than to actual block marginal price, which is costly to determine. ${ }^{12}$ Using household-level data, Borenstein (2008, 2009) and Ito (2010) also support the hypothesis that households tend to respond to average price.

Depending on the nature of the data used, using the average price, however, can create an endogeneity problem. If micro-level data are used, two-part and block pricing schemes mean that the average price depends on the quantity consumed by the household, and are therefore endogenous with one another. At the aggregate level, however, Shin (1985) argues that the potential for the price to be endogenous with consumption-issue ii) above-is mitigated by the presence of many different pricing levels and schemes at different locales.

We are, however, concerned about iii), the issue of measurement error. Our price variable is computed by the U.S. Energy Information Administration (EIA) as the average revenue per kWh of sales by all electric power retailers to a State. For this reason, we are concerned that it

\footnotetext{
${ }^{11}$ Some utilities also use time-of-use rates. It would be interesting to analyze household electricity demand by timeof-use using aggregate data at the state level, but to our knowledge the data needed for this type of analysis are not available for the US. In the literature, there are only few studies that analyze the residential electricity demand by time-of-use using aggregate data. See Filippini $(1995,2010)$.

${ }^{12}$ Typically the US electric utilities utilize a block rate design. This implies that the marginal price for each household varies with the quantity of electricity consumed, and can vary from season to season, making it difficult for a household to keep track of it.
} 
might be affected by measurement error. For starters, the EIA does sometimes "miss" some retail electricity suppliers. Second, the electric power retailers in a state may apply different tariff structures (block pricing, time-of-use pricing) that are poorly reflected in the data. Third, the EIA data are an ex post annual average, but consumers may make their decisions based on expected prices (Borenstein, 2008, 2009; Ito, 2010).

Standard econometric theory shows when a regressor is mismeasured, and the measurement error is classical (i.e., the measurement error has mean zero and is uncorrelated with the true regressor and with the econometric error term in the regression), the estimated regression coefficient is biased towards zero (Greene, 2007, p. 325). Here, this would make the demand appear to be more inelastic to price than it truly is.

How can one get around the problem of a mismeasured regressor? Suppose it was possible to find another measure of price, and that this new measure of price was also affected by measurement error. Let $p_{i t}$ be true price, and let observed price be $p_{i t}^{*}=p_{i t}+e_{i t}$, where $e_{i t}$ is a classical measurement error (i.e., a disturbance term with mean zero and constant variance that is uncorrelated with true price and with all other variables in the regression equation). Let $r_{i t}^{*}$ be the additional proxy for price, with $r_{i t}^{*}=p_{i t}+u_{i t}$, with $u_{i t}$ a classical measurement error. It can be shown that the covariance between these two mismeasured price variables is the variance of true price (i.e., $\operatorname{Var}\left(p_{i t}\right)$ ), and this information can be used to correct the bias of the estimated coefficient on mismeasured price (Black and Kniesner, 2003).

Alternatively, $r_{i t}^{*}$ can be used to instrument for $p_{i t}^{*}$ and produce consistent estimates of the coefficient on $p_{i t}^{*}$. In this paper, we use lagged prices (up to two lags) to instrument for 
current prices. In sum, in the dynamic specification we combine instrumental variable estimation

for one regressor, price, within the Blundell-Bond estimation of equation (13). ${ }^{13}$

\section{Estimation Results}

Table 2 displays the regression results for the static model. We account for unobserved heterogeneity by using fixed effects (and the LSDV estimation technique) in column (A) and random effects in column (B). All of the coefficients have the expected signs and are statistically significant. The "within" estimator produces slightly smaller price elasticities, but the GLS and within estimates are close (within $15 \%$ of each other). These results are in line with the results from the earlier literature.

Table 2. Estimation results: Static Model.

\begin{tabular}{|c|c|c|c|c||}
\hline \multirow{2}{*}{$\begin{array}{c}\text { Dependent variable: log residential } \\
\text { electricity consumption per capita }\end{array}$} & \multicolumn{2}{|c|}{$\begin{array}{c}\text { (A) } \\
\text { Fixedfects Model }\end{array}$} & \multicolumn{2}{c|}{$\begin{array}{c}\text { Random Effects } \\
\text { Model (GLS) }\end{array}$} \\
\hline & Coeff. & T stat & Coeff. & T stat \\
\hline Intercept & 4.1042 & 10.36 & 5.1031 & 12.44 \\
\hline Lnpel & -0.2179 & -12.03 & -0.2536 & -13.25 \\
\hline Lnpgas & 0.0486 & 4.73 & 0.0583 & 5.29 \\
\hline Lnic & 0.2839 & 9.35 & 0.2171 & 6.83 \\
\hline Lnhs & -0.7476 & -7.89 & -0.7703 & -7.87 \\
\hline LnHDD & 0.1472 & 7.42 & 0.0948 & 4.78 \\
\hline LnCDD & 0.0799 & 10.21 & 0.0864 & 10.35 \\
\hline & & & & \\
\hline sample size & 624 & & 624 & \\
\hline R square within & 0.7970 & & 0.7918 & \\
\hline R square between & 0.0652 & & 0.3401 & \\
\hline R square overall & 0.1010 & & 0.3270 & \\
\hline
\end{tabular}

\footnotetext{
${ }^{13}$ Our use of past prices as instruments is in contrast with Alberini et al. (forthcoming), where the instrument for individual prices is the state-level average price.
} 
Table 3 displays the regression results for the dynamic model obtained using i) conventional LSDV, ii) LSDVC, iii) a selected variant of the BB-GMM (BB-GMM-1), and iv) a version of the BB-GMM (BB-GMM-2) where we instrument for price, which is endogenous if it is measured with error. Although we expect i) to be biased, we report it in table 4 for comparison purposes.

Most of the coefficients in the LSDV model have the expected signs and are statistically significant. However, as mentioned, due to the correlation between the lagged dependent variable and the error term, we expect the LSDV estimates to be biased and inconsistent.

The majority of the coefficients in the LSDVC model and in the BB-GMM-1 and BBGMM-2 models have the expected signs and are statistically significant. Moreover, the p-value of the test statistics of serial correlation (for AR1 and AR2 processes) and overidentifying restrictions (Sargan) show that in the two BB-GMM models there is no significant second-order autocorrelation, which is crucial for the validity of the instruments. Furthermore, the p-value of the Sargan test statistic indicates that the null hypothesis that the overidentifying restrictions are valid is not rejected.

The results are comforting in that the coefficients on the price variables and that on the lagged dependent variable (which are used to compute the long-run elasticities) are significant and carry the expected signs in all models. The magnitude of the electricity price coefficients obtained using the LSDV, corrected LSDV, and Blundell-Bond GMM that instruments for electricity prices are relatively similar. This implies that the short-run elasticities will also be similar. It is striking that the Blundell-Bond GMM technique that assumes prices to be 
exogenous produces a short-run elasticity that is only half as large as those from the other techniques.

As expected, the coefficient on the lagged dependent variable changes dramatically from one estimation procedure to the next. The LSDVC coefficient on this variable is about $36 \%$ larger than its LSDV counterpart. The two Blundell-Bond procedures results in estimated coefficients of 0.81 and 0.79 , respectively. These two coefficients are very similar to one another, and represent a $19 \%$ increase over the LSDVC estimate, which in turn is larger than the LSDV estimate.

Based on these findings, we expect the long-term elasticities to be largest with Blundell-Bond GMM-2, and indeed this expectation is borne out in the elasticity figures displayed in table 4. Table 4 reports the estimates of the short and long-run own price elasticities, along with standard errors around them, for the consistent estimators of table 3. The estimated short-run own price elasticities vary between -0.08 and -0.15 . These values imply that at least in the short-run, raising the price of electricity does not create much of an incentive for customers to decrease electricity consumption. Low as they might be, -0.15 is (in absolute magnitude) $88 \%$ larger than -0.08 . 
Table 3. Dynamic Model. Dependent variable: log residential electricity consumption per capita

\begin{tabular}{|c|c|c|c|c|c|c|c|c|}
\hline & \multicolumn{2}{|c|}{ LSDV } & \multicolumn{2}{|c|}{ LSDVC } & \multicolumn{2}{|c|}{ BB-GMM1 } & \multicolumn{2}{|c|}{ BB-GMM2 } \\
\hline & Coeff. & t stat. & Coeff. & t stat. & Coeff. & t stat. & Coeff. & t stat. \\
\hline intercept & 1.858311 & 4.05 & & & 1.258141 & 1.38 & 0.483547 & 0.48 \\
\hline lagged Inelpc & 0.49761 & 15.25 & 0.682531 & 19.64 & 0.811038 & 18.34 & 0.791011 & 23.63 \\
\hline Lnpel & -0.15842 & -9.85 & -0.13812 & -8.04 & -0.08317 & -2.24 & -0.15235 & -3.55 \\
\hline Lnpgas & -0.03068 & -2.55 & -0.02745 & -1.87 & 0.018566 & 0.86 & 0.008243 & 0.38 \\
\hline Lnic & 0.063719 & 1.78 & 0.052963 & 1.04 & -0.09284 & -1.29 & 0.045463 & 0.45 \\
\hline Lnhs & -0.21625 & -2.68 & -0.14794 & -1.32 & 0.004938 & 0.03 & -0.2847 & -1.7 \\
\hline Lnhdd & 0.093101 & 4.68 & 0.095626 & 4.56 & 0.065177 & 2.89 & 0.028774 & 1.4 \\
\hline Lncdd & 0.072958 & 10.65 & 0.076846 & 9 & 0.07682 & 5.91 & 0.06648 & 5.48 \\
\hline 1997 year dummy & -0.02605 & -5.83 & -0.0301 & -5.76 & -0.03667 & -5.79 & -0.04352 & -6.52 \\
\hline 1998 year dummy & -0.00831 & -1.43 & -0.00886 & -1.21 & 0.000143 & 0.01 & -0.02003 & -1.68 \\
\hline 1999 year dummy & -0.01571 & -2.7 & -0.01883 & -2.42 & -0.01875 & -1.99 & -0.04026 & -3.06 \\
\hline 2000 year dummy & 0.002348 & 0.37 & -0.00103 & -0.13 & 0.006231 & 0.47 & -0.02339 & -1.31 \\
\hline 2001 year dummy & -0.00579 & -0.72 & -0.01455 & -1.35 & -0.02173 & -1.18 & -0.04763 & -1.87 \\
\hline 2002 year dummy & 0.011643 & 1.49 & 0.003198 & 0.29 & 0.013855 & 0.72 & -0.02027 & -0.83 \\
\hline 2003 year dummy & -0.00125 & -0.14 & -0.01664 & -1.42 & -0.01375 & -0.66 & -0.05044 & -1.75 \\
\hline 2004 year dummy & 0.016889 & 1.66 & 0.002225 & 0.17 & 0.006182 & 0.27 & -0.03573 & -1.1 \\
\hline 2005 year dummy & 0.044141 & 3.89 & 0.027436 & 1.78 & 0.023867 & 0.9 & -0.01469 & -0.42 \\
\hline 2006 year dummy & 0.02346 & 1.82 & -0.00127 & -0.07 & -0.02057 & -0.78 & -0.06262 & -1.72 \\
\hline 2007 year dummy & 0.046243 & 3.85 & 0.024211 & 1.49 & 0.024613 & 0.91 & -0.01721 & -0.46 \\
\hline Sargan test ( $p$-value) & & 0.0000 & & & & 0.9922 & & 0.1016 \\
\hline Arellano-Bond ARl test (p-value & & 0.0000 & & & & 0.0000 & & 0.0000 \\
\hline Arellano-Bond AR2 test (p-value) & & 0.2204 & & & & 0.2204 & & 0.1159 \\
\hline
\end{tabular}

Note: BB-GMM-1 instruments for lag electricity up to second lags. BB-GMM-2 treats lag electricity and log price as endogenous. Instruments for lag electricity up to second lags and instruments for the price variable first and second lags. Note: Robust standard errors has been used for the computation of the $t$-values.

Sargan test from Two-Step Estimator. 
The story is much less clear-cut for the long-run elasticity. The estimated long-run own electricity price elasticities is approximately - 0.43 in the LSDVC and BB-GMM-1 and 0.73 in the BB-GMM-2. The difference is striking (70\%), and is mainly due to the fact that the different estimators produce widely different estimates of the coefficient on the lagged demand variable. Because the LSDVC and BB-GMM-1 estimators suffer from the bias determined by the measurement error of the electricity price variable, we regard BB-GMM-2 as the most appropriate estimation technique and its coefficient estimates as the most reliable. For this model, the own price elasticity is high enough that the impact of an increase of the electricity price on electricity consumption is relatively important, at least in the long run, and that a pricing policy holds promise.

Table 4. Short and long-run elasticities implied by the dynamic models.

\begin{tabular}{||l|l|l|l||}
\hline \hline own price elasticity & LSDVC & BB-GMM-1 & BB-GMM-2 \\
\hline short run & -0.13812 & -0.08317 & -0.15235 \\
\hline long run & -0.43508 & -0.44219 & -0.72898 \\
\hline st err (LR elasticity) & 0.127850 & 0.20996 & 0.191381 \\
\hline
\end{tabular}

\section{Conclusions}

In this study, we have examined the demand for electricity in the residential sector in the US. For this purpose, a log-log static and a log-log dynamic model for electricity consumption were estimated using annual state-level data for 48 states over 13 years.

Several estimation techniques are possible for static and dynamic panel data models. Our dataset is characterized by a relatively small $\mathrm{N}$ and $\mathrm{T}$, so we must choose the econometric 
estimation technique judiciously. We use the LSDVC estimator proposed by Kiviet and the “system" GMM estimator proposed by Blundell and Bond (1998). Moreover, to remedy a possible measurement error in the electricity price variable, which makes state-level price and residential electricity econometrically endogenous, we also used a dynamic specification that combine instrumental variable estimation for one regressor, price, within the Blundell-Bond “system” estimation.

The short-run elasticities vary between -0.08 and -0.15 , and the long run price elasticities between -0.45 and -0.75 . Changing the estimation technique alone, therefore, changes the estimated elasticities by $70 \%-88 \%$. Our preferred estimation technique is the Blundell-Bond that instruments for price, because it is stable, efficient and "safe" if the price is mismeasured, as we argue is the case. Neglecting this latter problem would understate the responsiveness to price, and indeed when we instrument for price to correct for the measurement error, the demand is more elastic.

From an energy policy point of view, the results obtained using the version of the BBGMM (BB-GMM-2), where we instrument for price, imply that there is room for discouraging residential electricity consumption using price increases. Energy price increases may be attained, for example, by raising the tax levied per KWh sold. In an electricity system mainly based on power plants that burn fossil fuels, they may also result from imposing a carbon tax to curb greenhouse gas emissions (National Academy of Sciences, 2010) or follow from the implementation of a cap-and-trade program (US EPA, 2009, 2010; Congressional Budget Office, 2009). In the latter two cases, the reduction in energy consumption would presumably achieve additional reductions in $\mathrm{CO} 2$ and conventional pollutant emissions with respect to those attained with the mere shift towards cleaner sources. 


\section{References}

Alberini, A., W. Gans, and D. Velez-Lopez (2011), "Residential Consumption of Gas and Electricity in the U.S.: The Role of Prices and Income," forthcoming in Energy Economics.

Anderson, T.W. and C. Hsiao (1982). "Formulation and Estimation of Dynamic Models Using Panel Data". Journal of Econometrics, 18 (1), 47-82.

Arellano, M. and S. Bond (1991). "Some Tests of Specification for Panel Data: Monte Carlo Evidence and an Application to Employment Equations". Review of Economic Studies, 58, 277-297.

Balestra, P. and M. Nerlove (1966). "Pooling Cross-Section and Time Series Data in the Estimation of a Dynamic Model: The Demand for Natural Gas”. Econometrica, 34 (3), 585-612.

Baltagi, B.H. (2001). Econometric Analysis of Panel Data. Chichester: Wiley \& Sons.

Baltagi, B.H., G. Bresson, and A. Pirotte (2002). "Comparison of Forecast Performance for Homogeneous, Heterogeneous and Shrinkage Estimators: Some Empirical Evidence from U.S. Electricity and Natural Gas Consumption”. Economics Letters, 76 (3), 375382.

Berry, D. (2008). "The Impact of Energy Efficiency Programs on the Growth of Electricity Sales". Energy Policy, 36 (9), 3620-3625

Bernstein, M.A., and J. Griffin (2005). "Regional Differences in Price-Elasticity of Demand for Energy". The Rand Corporation Technical Report.

Blundell, R. and S. Bond (1998). "Initial Conditions and Moment Restrictions in Dynamic Panel Data Models". Journal of Econometrics, 87 (1), 115-143.

Cameron, A. C. and P. K. Trivedi (2005). Microeconometrics: Methods and Applications. Cambridge, UK: Cambridge University Press

Cameron, A. C. and P.K. Trivedi (2010). Microeconometrics using Stata. College Station, TX: STATA Press.

Congressional Budget Office (2009). "The Economic Effects of Legislation to Reduce Greenhouse Gas Emissions". Statement of Douglas Elmendorf before the Committee on Energy and Natural Resources, United States Senate, available at http://www.cbo.gov/ftpdocs/105xx/doc10561/10-14-Greenhouse-GasEmissions.pdf (accessed 19 July 2010).

Deaton, A. and J. Muellbauer (1980). Economics and Consumer Behavior. Cambridge: Cambridge University Press. 
Espey, J.A. and M. Espey (2004). "Turning on the Lights: A Meta-Analysis of Residential ElectricityDemand Elasticities". Journal of Agricultural and Applied Economics, 36 (1), 65-81.

Fell, Harrison, Shanjun Li, and Anthony Paul (2010), "A New Look at Residential Electricity Demand Using Household Expenditure Data," RFF Discussion paper 10-57, Washington, DC, October.

Flaig, G. (1990). "Household Production and the Short-Run and Long-run Demand for Electricity”. Energy Economics, 12 (2), 116-124.

Filippini, M. (1995), 'Swiss Residential Demand for Electricity by Time-of-Use', Resource and Energy Economics, 17, pp. 281-290.

Filippini, M. (1999). “Swiss Residential Demand for Electricity”. Applied Economic Letters, 6 (8), 533-538.

Filippini, M. (2010), 'Short and long-run time-of-use price elasticities in Swiss residential electricity demand, CEPE Working paper.

Greene, W.H. (2008). Econometric Analysis. Sixth Edition. Upper Saddle River, NJ: Prentice Hall.

Halvorsen, R. (1975) "Residential Demand for Electric Energy". The Review of Economics and Statistics, 57 (1), 12-18.

Harris, M., S. L. Matyas, and P. Sevestre (2008). Dynamic Models for Short Panels, in MatyasSevestre (eds.). The Econometrics of Panel Data, Third Edition, Darmstadt, Germany: Springer-Verlag, 249-278.

Hayakawa, K. (2007). "Small Sample Bias Properties of the System GMM Estimator in Dynamic Panel Data Models". Economics Letters, 95 (1), 32-38.

Houthakker, H. S. (1980). “Residential Electricity Revisited”. Energy Journal, 1 (1), 29-41.

Judson, R.A. and A.L. Owen (1999). "Estimating Dynamic Panel Data Models: A Guide for Macroeconomists". Economic Letters, 65 (1), 9-15.

Kamerschen, D.R., and D.V. Porter (2004). "The Demand for Residential, Industrial, and Total Electricity, 1973-1998”. Energy Economics, 26 (1), 87-100.

Kiviet, J.F. (1995). “On Bias, Inconsistency, and Efficiency of Various Estimators in Dynamic Panel Data Models," Journal of Econometrics, 68 (1), 53-78.

National Academy of Science (2010). Limiting the Magnitude of Future Climate Change, Washington, DC: The National Academies Press. 
Nickell, S. (1981). "Biases in Models with Fixed Effects". Econometrica, 49 (6), 1417-1426.

Paul, A., E. Myers, and K. Palmer (2009). "A Partial Adjustment Model of U.S. Electricity Demand by Region, Season, and Sector". Resource for the Future Discussion Paper 08-50, Washington, DC, April.

Shin, J.S. (1985). "Perception of Price When Price Information Is Costly: Evidence from Residential Electricity Demand". The Review of Economics and Statistics, 67 (4), 591598

Taylor, L.D. (1975). “The Demand for Electricity: A Survey”. Bell Journal of Economics 6 (1), 74-110.

Uri, N. (1994). "The Impact of Measurement Error in the Data on Estimates of the Agricultural Demand for Electricity in the USA". Energy Economics, 16 (2), 121-131.

U.S. Environmental Protection Agency (2009). "EPA Analysis of the American Clean Energy and Security Act of 2009, H.R. 2454 in the $111^{\text {th }}$ Congress," available at http://www.epa.gov/climatechange/economics/pdfs/HR2454_Analysis.pdf (accessed 19 July 2010).

U.S. Environmental Protection Agency (2010). "EPA Analysis of the American Power Act in the $111^{\text {th }} \quad$ Congress," available at http://www.epa.gov/climatechange/economics/pdfs/EPA_APA_Analysis_6-14-10.pdf (accessed 19 July 2010).

Thomas, R.L. ,1987. Applied Demand Analysis, Longman.

US Bureau of Labor Statistics. "Consumer Price Index," http://www.bls.gov/cpi/ (accessed 18 July 2010).

Xiao N., Zarnikau J. and Damien P.(2007), “ Testing functional forms in energy modelling: An application of the Bayesian approach to U.S. electricity demand" Energy Economics 29 158-166 